\title{
Glaucoma Quality of Life-15 Questionnaire to Assess the Functional Disability in Egyptian Glaucomatous Patients
}

\author{
Tarek T. Aboulnasr, Ahmed M. Saeed, Mohamed A. Behery
}

Department of Ophthalmology, Benha faculty of medicine, Benha University, Egypt.

Correspondence to: Mohamed

A. Behery, Department of Ophthalmology, Benha faculty of medicine, Benha University, Egypt

Email:

m.behery760@gmail.com

Received: 14 February, 2020

Accepted: 4 May 2021

\begin{abstract}
Purpose: To assess and compare the functional disability in patients with primary open angle glaucoma (POAG) using the glaucoma quality of life-15 questionnaire (GQL-15) and to evaluate their quality of life. Methods: 175 patients with POAG and 175 subjects with age- and sex-matched (control group) were enrolled in this cross-sectional study. Glaucoma quality of Life-15 questionnaire was administered in local Egyptian language via interviews after doing standard tests for visual function for both groups. Results: The median GQL-15 score in the glaucoma cases (34) was significantly higher (indicating more functional disability) than the controls (17). All subscale scores also showed a regular rise in their value as the glaucoma increased in severity from mild to severe. There were visual disability in certain tasks related to glare and dark adaptation
\end{abstract} which appeared to be early affected during the course of glaucoma. Activities demanding peripheral vision, near and central vision and outdoor mobility affected later but were more significant with the progression of the disease. Conclusion: Glaucoma patients have many functional disabilities with challenges in performing many tasks which reflects on their independence and productivity. This knowledge can be helpful to learn the newly diagnosed and to increase the adherence to treatment aiming to guard against the disease progression; also it suggests adaptations to the patient's environment for better quality of life.

Key words: glaucoma, quality of life, Glaucoma Quality of Life-15 Questionnaire, GQL-15. 


\section{Introduction}

The World Health Organization (WHO) defines Quality of Life (QOL) as an "individuals' perceptions of their position in life in the context of the culture and value systems in which they live and in relation to their goals, expectations, standards and concerns". ${ }^{(1)}$ It is a complex concept that is affected by the person's psychological state, physical health, level of independence, social relationships, and surrounding environment. It reflects the difference between the hopes and expectations of a person and their present experience. ${ }^{(2)}$

Glaucoma is a progressive optic neuropathy that results in irreversible loss of the visual field (VF). It is the world's second leading cause of irreversible blindness. ${ }^{(3)}$ Glaucoma can lead to deterioration of quality of life due to many reasons; the diagnosis itself with its psychological effects (anxiety, depression, and fear of blindness), the hard adherence to daily treatment, the side effects of topical medication (as dry eye, redness, blepharitis, allergic conjunctivitis), the progressive visual field loss, the constrictions concerning daily activities, the financial problems (as cost of treatment and investigations) and the need of regular lifelong follow-up on an outpatient basis are some of these causes. (4) Physicians diagnosing glaucoma generally rely on the values obtained by clinical measurements which are made under controlled clinic conditions as objective assessments of visual function. But these measurements do not assess patient experience of visual related quality of life (VR-QOL) involved in the tasks of daily life and work, including reading, walking, driving, and other activities. ${ }^{(5)}$

Increasingly, patient-reported outcomes are being used to estimate the impact of a disease on VR-QOL, which includes not only the biologic status of disease but also the full range of outcomes, such as mental health, social function and role difficulties. (6) The patient's perception becomes a central determinant in monitoring the outcomes of medical intervention. (7) Moreover, the US Food and Drug Administration have recently placed emphasis on patient-reported outcome (PRO) measures in clinical studies. ${ }^{\left({ }^{8}\right)}$

Several instruments have been developed to assess the impact of glaucoma from the patient's perspective or to measure Selfperceived vision-related QoL in glaucoma patients. These include generic health- 
related, vision-specific and glaucomaspecific questionnaires. ${ }^{(9)}$ Generic healthrelated instruments as Medical outcomes study short form-36 (SF-36) ${ }^{(10)}$ and The sickness impact profile (SIP) ${ }^{(11)}$ try by nature to estimate the overall quality of life of subjects, without taking into account separate coexisting diseases or assessing how they individually impact QoL. It is rather difficult to attribute possible decreased QoL scores recorded by general health-related instruments only to glaucoma. ${ }^{(9)}$ Vision-specific instruments as Visual Function Questionnaire-14 (VFQ-14) (12) ,The National Eye Institute Visual Function Questionnaire (NEIVFQ) ${ }^{(13)}$ and The 25-Item National Eye Institute Visual Function Questionnaire (NEI-VFQ25) ${ }^{\text {(14) }}$ were developed with the primary goal of assessing the effect of cataract on patients' perceived visual ability .

Glaucoma-specific instruments include The Glaucoma Symptom Scale (GSS) ${ }^{(15)}$, The Comparison of Ophthalmic Medication for Tolerability (COMTOL) Scale ${ }^{(16)}$, The Glaucoma Quality of Life-15 (GQL-15) ${ }^{(17)}$, The Symptom Impact Glaucoma Score (SIG) and Glaucoma Health Perceptions Index (GHPI). ${ }^{(18)}$. The glaucoma-specific instruments can significantly discriminate between glaucoma patients and controls.
These instruments appear to be more related to objective (clinical) measures of the disease state than the generic or the vision specific instruments. ${ }^{(9)}$

GQL-15 showed excellent validation features (Internal consistency, test-retest reliability), while significant correlations were found between GQL-15 responses and a number of psychophysical measurements of visual function. ${ }^{(17)}$ It is concise and easy to administer. It has been translated and adapted for usage in many languages and populations. The GQL-15 (Glaucoma Quality of Life-15) questionnaire is composed of 15 items, 4 domains which address factors of visual disability: Central and near vision, Peripheral vision, Dark adaptation and glare, and Outdoor mobility. (17)

\section{Subjects and methods}

This prospective cross-sectional analytical study was performed during the period between May 2017 and April 2019. The study included 175 patients with POAG and 175 control subjects without glaucoma who attended at Ophthalmology Department, Benha University Hospital and Giza Memorial Institute of Ophthalmology. Inclusion criteria for patients were previous diagnosis as POAG one month at least 
before the study, no other eye diseases that affect the vision, and normal mobility, cognition and hearing. Exclusion criteria for patients were presence of other ocular diseases that affect vision, other types of glaucoma, and presence of problems with mobility, cognition and hearing. Inclusion criteria for controls included no family history of glaucoma, normal appearing optic nerve head, normal IOP by applanation tonometry and normal eye with normal refraction $(\mathrm{CDVA}>619)$.

Approval from research ethics committee in Benha faculty of medicine was obtained. The procedure was first explained to the patients and an informed consent form was signed.

All patients accepted in this study were previously diagnosed as POAG in both eyes and underwent history taking including general (Sociodemographic characteristics of the patients including age, gender, educational level and occupation), medical, ophthalmic and glaucoma history. Cases and controls underwent a standard ophthalmic examination including best corrected visual acuity (BCVA), slit lamp examination of the anterior segment of the eye, IOP measurement using applanation tonometry, slit lamp examination of the anterior chamber angle with 3-mirror gonio-lens and Funds examination with non-contact bio-microscopy.

All the patients underwent visual field assessment with an automated Humphrey visual field analyzer (Carl Zeiss Meditec Inc., Dublin, CA, USA) using SITA (Swedish interactive threshold algorithm) strategy. The patients were classified into three groups using a standard grading system: Hodapp-Anderson-Parrish (HAP) grading scale. The MD was used as VF measurement representing overall VF loss, and the worst MD between the two eyes (worst MD) was used to classify the severity of the VF loss. Hence, patients were categorized into three groups : (1) mild, with MD of no worse than $-6 \mathrm{~dB}$; (2)moderate, with $\mathrm{MD}$ of -6 to $-12 \mathrm{~dB}$; and (3) severe, with MD worse than $-12 \mathrm{~dB}$.

The GQL-15 questionnaire is composed of 15 items, which addresses 4 factors of visual disability: (1) peripheral vision (Six questions); (2) dark adaptation and glare (Six questions) ; (3) central and near vision (two questions) ; and (4) outdoor mobility(one question). For the GQL-15 summary scores, item-level responses for each factor were coded on a scale of 0 to 5 , wherein 0 signified abstinence from activity owing to nonvisual reasons, 1 indicated no 
difficulty, and 5 represented severe difficulty.

\section{Statistical analysis}

The clinical data were recorded on a report form. These data were tabulated and analysed using the computer program SPSS vs.20. (IBM, Armonk, New York, United states) to obtain descriptive data and analytical statistics.

Descriptive data included mean and standard deviation SD; Median and inter-quartile range (IQR) for quantitative data; and Frequency and distribution for qualitative data. Regarding analytical statistics, in the statistical comparison between the different groups, the significance of difference was tested using one of the following tests after establishing their non normality by $\mathrm{K}-\mathrm{S}$ test (One-Sample KolmogorovSmirnov Test) of normality: (1) Student's t-test and Mann-Whitney test: Used to compare mean of two groups of quantitative data of parametric and non parametric respectively; (2) ANOVA test (F value) and Kruskal-Wallis test: Used to compare mean of more than two groups of quantitative data of parametric and non- parametric respectively; and (3) chi square test $\left(\mathrm{X}^{2}\right.$-value) and fisher exact test (FET): for inter-group comparison of categorical data. A $\mathrm{P}$ value $<0.05$ was considered statistically significant $(*)$ while $>0.05$ statistically insignificant $\mathrm{P}$ value $<0.01$ was considered highly significant $(* *)$ in all analyses.

\section{Results}

In this study, 175 patients with POAG and 175 control subjects without glaucoma were enrolled. The mean age of all participants was $55.94 \pm 10.29$ years. As presented in table (1), there were proportionately more females among the cases $(58.0 \%)$ compared to the controls $(47.4 \%) \quad(\mathrm{p}=0.042)$. No significant difference was found with respect to the age. The mean age of the cases was 55.86(SD \pm 8.86) and controls was 56.02 years (SD $\pm 11.57)$. The educational level distribution of the cases and controls was highly comparable. There was some evidence of a difference in the occupation, with $(63.4 \%)$ of the controls were with occupation while $56.0 \%$ of the cases were without occupation. 
Table (1): Socio-demographic characteristics of the case and control groups.

\begin{tabular}{|c|c|c|c|c|c|c|}
\hline & \multicolumn{2}{|c|}{ Case group (175) } & \multicolumn{2}{|c|}{ Control group (175) } & \multirow{2}{*}{$\begin{array}{l}\text { Statistical } \\
\text { test }\left(\mathrm{x}^{2}\right)\end{array}$} & \multirow[t]{2}{*}{$P$ value } \\
\hline & No & $\%$ & & $\%$ & & \\
\hline \multicolumn{7}{|l|}{$\overline{\text { Sex }}$} \\
\hline Male & 73 & 41.7 & 92 & 52.6 & 4.14 & $0.042 *$ \\
\hline Female & 102 & 58.3 & 83 & 47.4 & & \\
\hline $\begin{array}{l}\text { Age Mean } \pm \text { SD } \\
\text { (range) yrs }\end{array}$ & \multicolumn{2}{|c|}{$55.86 \pm 8.86(31-75)$} & \multicolumn{2}{|c|}{$56.02 \pm 11.57(31-76)$} & St $\mathrm{t}=0.15$ & 0.89 \\
\hline \multicolumn{7}{|l|}{ Educational level } \\
\hline Illiterate & 71 & 40.6 & 58 & 33.1 & 7.65 & 0.054 \\
\hline Low & 46 & 26.3 & 34 & 19.4 & & \\
\hline Moderate & 27 & 15.4 & 41 & 23.4 & & \\
\hline High & 31 & 17.7 & 42 & 24.0 & & \\
\hline \multicolumn{7}{|l|}{ Occupation } \\
\hline Yes & 77 & 44.0 & 111 & 63.4 & 13.29 & $<0.001 * *$ \\
\hline No & 98 & 56.0 & 64 & 36.6 & & \\
\hline
\end{tabular}

The clinical characteristics of the cases are shown in Table (2). All cases had bilateral open angle glaucoma. The median duration of the glaucoma was 2.0 years. Their median visual field defect (MD) on HFA was $(-13.34 \mathrm{~dB})$. The three subgroups of the cases showed significant differences regarding the BCVA, duration of the disease, $\mathrm{C} / \mathrm{D}$ ratio and $\mathrm{MD}$. The mild group with median MD $(-3.14)$ had median
BCVA of (1.0), median C/D ratio (0.65) and median glaucoma duration of 1 year. The moderate group with median MD (8.33) had median BCVA of (0.8), median $\mathrm{C} / \mathrm{D}$ ratio (0.7) and mean glaucoma duration of 2 years. The sever group with median MD (-18.83) had median BCVA of 0.6, median C/D ratio (0.8) and median glaucoma duration of 3 years.

Table (2): clinical characteristics of the 3 subgroups of the cases.

\begin{tabular}{|c|c|c|c|c|c|c|c|c|}
\hline \multirow{2}{*}{$\begin{array}{l}\text { Case group } \\
\text { 175) }\end{array}$} & \multicolumn{2}{|c|}{ Mild (42) } & \multicolumn{2}{|c|}{ Moderate (53) } & \multicolumn{2}{|c|}{ Severe $(80)$} & \multirow{2}{*}{$\begin{array}{l}\text { Statistical } \\
\text { test }(\mathrm{KW})\end{array}$} & \multirow[t]{2}{*}{$P$ value } \\
\hline & Median & IQR & Median & IQR & Median & IQR & & \\
\hline BCVA & 1.0 & $0.9-1.0$ & $0.8 \mathrm{a}$ & $0.78-1.0$ & $0.68 \mathrm{ab}$ & $0.35-0.9$ & 52.86 & $<0.001 * *$ \\
\hline IOP & 14.0 & $12.5-15.0$ & 14.0 & $12.5-16.0$ & 13.5 & $12.0-17.0$ & 0.57 & 0.75 \\
\hline $\mathrm{C} / \mathrm{D}$ ratio & 0.65 & $0.6-0.7$ & $0.75 a$ & $0.7-0.8$ & $0.85 \mathrm{ab}$ & $0.8-0.9$ & 119.08 & $<0.001 * *$ \\
\hline $\begin{array}{l}\text { Duration } \\
\text { (yrs) }\end{array}$ & 1.0 & $0.58-3.0$ & $2.0 \mathrm{a}$ & $0.88-4.0$ & $3.0 \mathrm{ab}$ & $2.0-6.0$ & 80.27 & $<0.001 * *$ \\
\hline MD & -3.14 & $\begin{array}{l}-(5.76)-(- \\
2.43)\end{array}$ & -8.33 & $\begin{array}{l}(-9.75)-(- \\
6.93)\end{array}$ & -18.83 & $\begin{array}{l}(-23.3)-(- \\
14.08)\end{array}$ & $\mathrm{MW}=8.53$ & $<0.001 * *$ \\
\hline Total score & 20.0 & $17.75-22.0$ & $30.0 \mathrm{a}$ & $26.5-32.5$ & $45.0 \mathrm{ab}$ & $39.0-49.0$ & 20.46 & $<0.001 * *$ \\
\hline
\end{tabular}


The GQL-15 questionnaire scores of glaucoma cases and the controls are presented in Table (3). There are significant differences between cases and controls in all the items, the subscales and total score of the questionnaire. Patients with glaucoma reported significantly poorer G-QoL compared with controls $(\mathrm{P}<0.001)$. The median GQL-15 score for cases was (34.0) versus (17.0) for controls. Regarding the subscales, the highest differences were in the glare and dark adaption scale with the median of (16) for the cases versus (8) for the controls ; and in the peripheral vision scale with the median of (13)for the cases versus (6) for the controls Figure(1). Regarding the central and near vision scale, the cases had a median of (3) versus (2) for the control. The least difference was in the outdoor mobility scale with the cases had a median of (1.0) and IQR (1.0-2.0) while the controls had a median of (1.0) and IQR $(1.0-1.0)$.

Table (3): Comparison of GQL-15 Scores between cases and controls.

\begin{tabular}{|c|c|c|c|c|c|c|}
\hline & \multicolumn{2}{|c|}{ Case group (175) } & \multicolumn{2}{|c|}{ Control group (175) } & \multirow{2}{*}{$\begin{array}{l}\text { Statistical test } \\
(\mathrm{MW})\end{array}$} & \multirow[t]{2}{*}{ P value } \\
\hline & Median & IQR & Median & IQR & & \\
\hline Total & 34.0 & $23.0-45.0$ & 17.0 & $16.0-19.0$ & 14.33 & $<0.001 * *$ \\
\hline 1. Walking on uneven ground & 3.0 & $2.0-4.0$ & 1.0 & $1.0-1.0$ & 14.8 & $<0.001 * *$ \\
\hline 2. Walking on steps/stairs & 3.0 & $2.0-4.0$ & 1.0 & $1.0-1.0$ & 14.27 & $<0.001 * *$ \\
\hline $\begin{array}{l}\text { 3. Judging distance of foot to } \\
\text { step }\end{array}$ & 2.0 & $1.0-2.0$ & 1.0 & $1.0-1.0$ & 11.55 & $<0.001 * *$ \\
\hline 4. Tripping over objects & 2.0 & $1.0-2.0$ & 1.0 & $1.0-1.0$ & 10.15 & $<0.001 * *$ \\
\hline 5. Bumping into objects & 2.0 & $1.0-2.0$ & 1.0 & $1.0-1.0$ & 9.61 & $<0.001 * *$ \\
\hline $\begin{array}{l}\text { 6. Seeing objects coming } \\
\text { from the side }\end{array}$ & 2.0 & $2.0-3.0$ & 1.0 & $1.0-1.0$ & 14.31 & $<0.001 * *$ \\
\hline Peripheral vision & 13.0 & $9.0-18.0$ & 6.0 & $6.0-7.0$ & 14.36 & $<0.001 * *$ \\
\hline 7. Walking after dark & 3.0 & $2.0-4.0$ & 1.0 & $1.0-2.0$ & 14.72 & $<0.001 * *$ \\
\hline 8. Seeing at night & 3.0 & $2.0-4.0$ & 1.0 & $1.0-2.0$ & 13.86 & $<0.001 * *$ \\
\hline 9. Adjusting to dim lights & 2.0 & $2.0-3.0$ & 1.0 & $1.0-2.0$ & 12.43 & $<0.001 * *$ \\
\hline 10. Adjusting to bright lights & 2.0 & $1.0-2.0$ & 1.0 & $1.0-2.0$ & 3.43 & $<0.001 * *$ \\
\hline $\begin{array}{l}\text { 11. Going from light to dark } \\
\text { room or vice versa }\end{array}$ & 3.0 & $2.0-4.0$ & 2.0 & $1.0-2.0$ & 10.28 & $<0.001 * *$ \\
\hline $\begin{array}{l}\text { 12. Going from light to dark } \\
\text { room or vice versa }\end{array}$ & 2.0 & $1.0-3.0$ & 1.0 & $1.0-1.0$ & 12.97 & $<0.001 * *$ \\
\hline & 16.0 & $12.0-20.0$ & 8.0 & $7.0-9.0$ & 14.22 & $<0.001 * *$ \\
\hline Glare and dark adaptation & & & & & & \\
\hline 13. Recognizing faces & 1.0 & $1.0-2.0$ & 1.0 & $1.0-1.0$ & 10.49 & $<0.001 * *$ \\
\hline 14. Reading newspapers & 2.0 & $1.0-2.0$ & 1.0 & $1.0-1.0$ & 10.81 & $<0.001 * *$ \\
\hline Central and near vision & 3.0 & $2.0-4.0$ & 2.0 & $2.0-2.0$ & 11.31 & $<0.001 * *$ \\
\hline $\begin{array}{l}\text { 15. Crossing the road } \\
\text { (Outdoor mobility) }\end{array}$ & 1.0 & $1.0-2.0$ & 1.0 & $1.0-1.0$ & 10.0 & $<0.001 * *$ \\
\hline
\end{tabular}




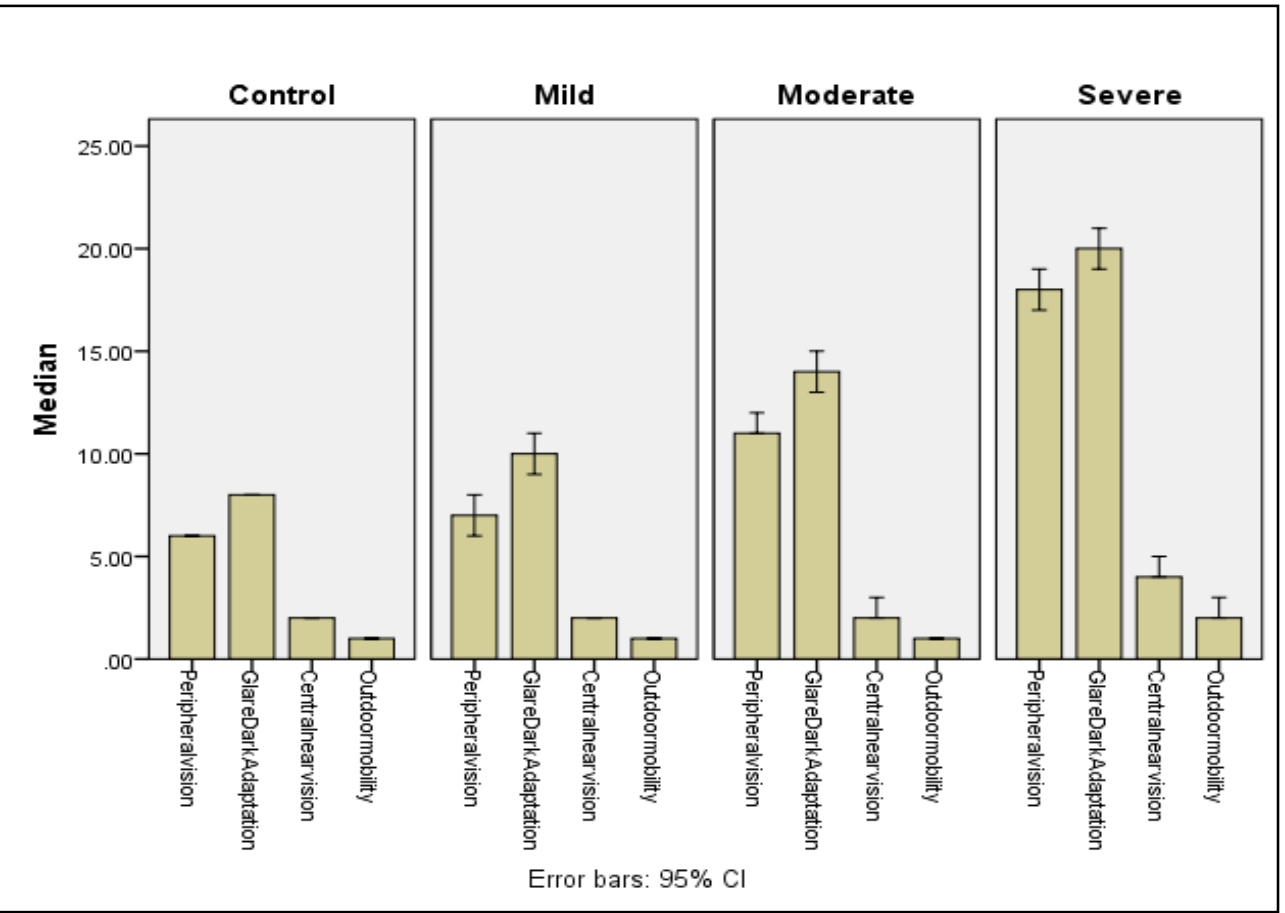

Figure (1): the median GQL-15 subscale scores for control and case subgroups

Regarding scores of the cases which are presented in table (4) and shown in figure (1), it is obvious that the total score of GQL-15 questionnaire increases as the severity of glaucoma increases. The median total score for the mild group was (20.0) while it was (30.0) for the moderate group. The severe group had the highest total score with the median total score (45.0). The differences between the cases were more obvious in the peripheral vision; and glare \& dark adaption subscales Figure (1). Regarding the central and near vision and outdoor mobility subscales, the differences were comparable between mild and moderate group and significant in comparison to severe group.

There were a statistically significant correlations between the total GQL-15 scores and each of age, BCVA and MD table (5). The strongest significant correlation was with MD (- 0.815, negative correlation) figure (2), then came the BCVA (- 0.678, negative correlation), and age at last (0.441, positive correlation). 
Benha medical journal vol. 39, special issue (ophthalmology), 2022

Table (4): Comparison of GQL-15 total and subscale Scores for the cases.

\begin{tabular}{|c|c|c|c|c|c|c|c|c|}
\hline \multirow[t]{2}{*}{ Case group (175) } & \multicolumn{2}{|c|}{ Mild (42) } & \multicolumn{2}{|c|}{ Moderate (53) } & \multicolumn{2}{|c|}{ Severe $(80)$} & \multirow{2}{*}{$\begin{array}{l}\text { Statistical } \\
\text { test }(\mathrm{KW}) \\
\end{array}$} & \multirow[t]{2}{*}{ P value } \\
\hline & Median & IQR & Median & IQR & Median & IQR & & \\
\hline Peripheral vision & 7.0 & $6.0-8.25$ & 11.0 & $10.0-13.0$ & 18.0 & $16.0-19.75$ & 140.1 & $<0.001 * *$ \\
\hline $\begin{array}{l}\text { Glare and dark } \\
\text { adaptation }\end{array}$ & 10.0 & $9.0-11.0$ & 14.0 & $12.0-16.0$ & 20.0 & $18.0-22.0$ & 139.91 & $<0.001 * *$ \\
\hline $\begin{array}{l}\text { Central and near } \\
\text { vision }\end{array}$ & 2.0 & $2.0-2.0$ & 2.0 & $2.0-4.0$ & 4.0 & $4.0-5.0$ & 87.51 & $<0.001 * *$ \\
\hline Outdoor mobility & 1.0 & $1.0-1.0$ & 1.0 & $1.0-2.0$ & 2.0 & $2.0-3.0$ & 79.25 & $<0.001 * *$ \\
\hline Total score & 20.0 & $17.75-22.0$ & 30.0 & $26.5-32.5$ & 45.0 & $39.0-49.0$ & 20.46 & $<0.001 * *$ \\
\hline
\end{tabular}

Table (5): Correlation between subscales and other variables among case group.

\begin{tabular}{|c|c|c|c|c|c|c|c|c|c|c|c|}
\hline & & Periph & l vision & $\begin{array}{l}\text { Glare } \\
\text { dark } \\
\text { adapt }\end{array}$ & $\begin{array}{l}\text { and } \\
\text { ion }\end{array}$ & $\begin{array}{l}\text { Centr } \\
\text { near v }\end{array}$ & ion & $\begin{array}{l}\text { Outdoor } \\
\text { mobility }\end{array}$ & & Total & \\
\hline & & Rho & $\mathbf{P}$ & rho & $p$ & Rho & $\mathbf{P}$ & Rho & $\mathbf{P}$ & Rho & $\mathbf{P}$ \\
\hline \multirow{3}{*}{$\begin{array}{l}\text { Total } \\
\text { Case } \\
\text { group } \\
\text { (175) }\end{array}$} & Age & 0.425 & $\begin{array}{l}<0.001 \\
* *\end{array}$ & 0.417 & $\begin{array}{l}<0.00 \\
1 * *\end{array}$ & 0.411 & $\begin{array}{l}<0.001 \\
* *\end{array}$ & 0.381 & $\begin{array}{l}<0.001 \\
* *\end{array}$ & 0.441 & $<0.001 * *$ \\
\hline & BCVA & -0.647 & $\begin{array}{l}<0.001 \\
* *\end{array}$ & $\begin{array}{l}- \\
0.629\end{array}$ & $\begin{array}{l}<0.00 \\
1 * *\end{array}$ & $\begin{array}{l}- \\
0.672\end{array}$ & $\begin{array}{l}<0.001 \\
* *\end{array}$ & -0.617 & $\begin{array}{l}<0.001 \\
* *\end{array}$ & -0.678 & $<0.001 * *$ \\
\hline & MD & -0.799 & $\begin{array}{l}<0.001 \\
* *\end{array}$ & $\begin{array}{l}- \\
0.776\end{array}$ & $\begin{array}{l}<0.00 \\
1 * *\end{array}$ & $\begin{array}{l}- \\
0.580\end{array}$ & $\begin{array}{l}<0.001 \\
* *\end{array}$ & -0.618 & $\begin{array}{l}<0.001 \\
* *\end{array}$ & -0.815 & $<0.001 * *$ \\
\hline
\end{tabular}

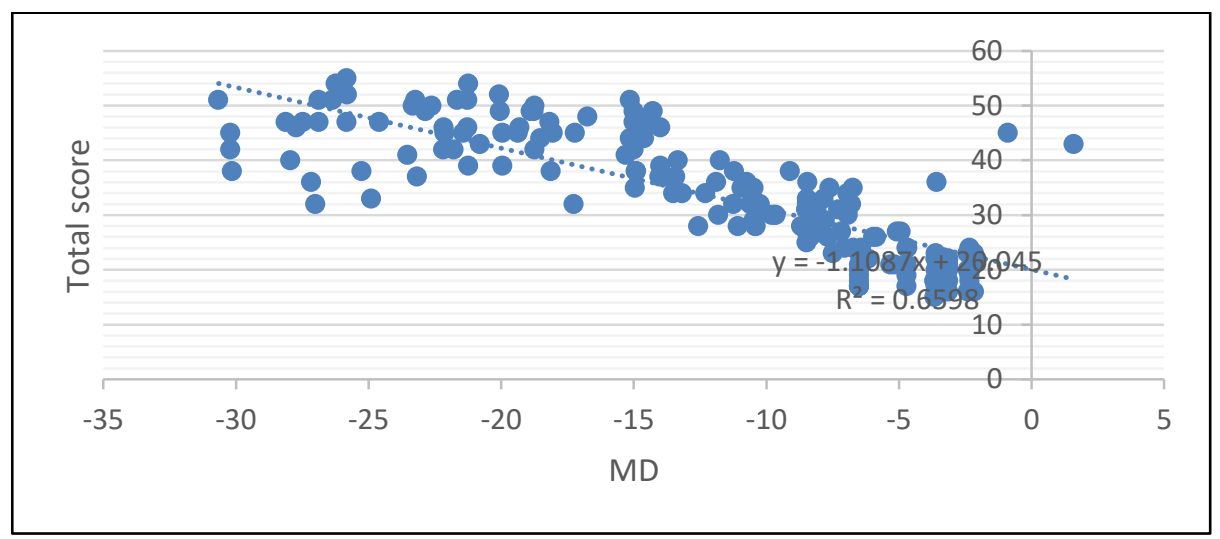

Figure (2): correlation between the total score and MD

\section{Discussion}

This study was done to assess the POAG patients. Because the GQL-15 is functional disability of the Egyptian glaucoma specific tool, the subscale scores 
allowed us to examine loss of GlaucomaQoL in the form of daily activities that may be especially troublesome for glaucoma patients. For activities requiring peripheral vision, glare and dark adaption, central and near vision, and outdoor mobility, the differences between patients with glaucoma and the control subjects were statistically significant. Moreover, among the glaucoma cases, patients experienced difficulty in daily visual functions that increased with increasing the glaucoma severity. This is consistent with the outcomes of other recent studies on this topic. (19-24)

In this study, the mean age was $(55.94 \pm 10.29)$ years with the mean age of the cases was $55.86(\mathrm{SD} \pm 8.86)$ and controls was 56.02 years $(\mathrm{SD} \pm 11.57)$ that appeared similar to the age group of other studies (19). Other study (20) had older numbers with the mean age of the patients with glaucoma was 70 [standard deviation (SD \pm 9.1 ) versus 63 years $(\mathrm{SD} \pm 8.9)$ for controls. Age had a negative impact on QOL which is consistent with the other studies.

There were proportionately more females among the cases $(58.0 \%)$ compared to the controls $(47.4 \%)$ which is consistent with other study $^{(20)}$.
The differences between glaucoma cases and controls were significantly higher in domains of glare and dark adaptation; and peripheral vision. This observation is consistent with other studies $(19,25)$. The most affected activities were that associated with dark adaptation or glare, like seeing at night, walking after dark, adjusting to different levels of illumination and peripheral vision activities such as walking on uneven grounds, walking on stairs, avoiding tripping over and bumping into objects, seeing objects coming from the side and judging distances. ${ }^{(19-25)}$

The median summary score of the controls in this study was (17) with IQR (16-19) which is higher than the mean scores of the controls in the Nigerian study (15.75) (19) and the Indian study (15.02) in. (22) This score was, however, lower than the scores of Australian study (18.5). (20) The median summary score of the GQL-15 in this study for the cases was 34.0 with IQR (23-45) which was found to be significantly higher than the mean scores of the Nigerian study (24.07) and the Australian study (30.5). ${ }^{(19,20)}$ But it was lower than the mean score of the Ethiopian study (46.3). ${ }^{(21)}$ 
These differences may be due to different sample sizes of patients (Egypt: 175 ;Ethiopia: 307; Nigeria: 132; Australia:121; India: 50) and subsequently variant sample of each subgroup for example number of patients with severe glaucoma (Egypt: 80; China: 133; Nigeria: 44; Australia: 38 ). It may be due to dissimilar patient selection criteria (this study included only patients with bilateral glaucoma in contrast to other studies that included patient with unilateral glaucoma), different methods for categorization of patients, and types of glaucoma (Egypt: POAG; China: POAG, NTG, PACG and SG; Nigeria: POAG; Ethiopia: POAG, PACG; Australia: POAG; India: chronic open/closed angle glaucoma). Finally the cultural and social variances may be a cause of the discrepancies.

The median summary scores of the case subgroups were (mild: 20; moderate: 30; and severe: 45). The differences in scores among the patients of different glaucoma stages were statistically significant , consistent with results of studies done in Australia ${ }^{(20)}(21.7,29.6,40)$, in India ${ }^{(22)}$ $(18.2,32.2,43.2)$, and in china ${ }^{(23)}(20.76$, 28.73, 44.55). However, the Nigeria study (19) did not find statistically significant differences between patients with mild and moderate glaucoma by using GQL-15 and the mean summery scores of the case subgroups were (mild: 18.98 ; moderate: 20.5 ;and sever: 32.65). Other study detected a significant difference in GQL-15 summary scores only between patients with mild and severe glaucoma. ${ }^{(25)}$ This could be because of dissimilar patient selection criteria as this study excluded patients with progressive disease and limited VA to between $6 / 9$ and $6 / 4$ in an attempt to reduce the influence of VA on their results which was not the case in this study or other studies. In addition, the effect of dissimilar patient selection criteria, different methods for categorization of patients and the different sociocultural levels could not be neglected.

Regarding the subscale scores, all the subscale scores showed a clear rise in their values as the glaucoma severity increased from mild to severe cases. The glare and dark adaptation subscale was the most disabling for patients with glaucoma and especially for the mild glaucoma patients who showed less affection by the other subscales. This finding is consistent with the Australian study ${ }^{(20)}$ and extends the observations of the Collaborative Initial Glaucoma Treatment Study (CIGTS), which also found this subscale to be the 
most troublesome for patients with early glaucoma. ${ }^{(18)}$

In this study, the differences between moderate and severe cases were significantly higher than the differences between mild and moderate cases regarding central and near vision; and outdoor mobility subscales. However, the Australian study ${ }^{(20)}$ found that patients with severe glaucoma were relatively less restricted by activities involving central and near vision or peripheral vision, but felt disabled by those involving outdoor mobility. And the study suggested that certain functional problems become less pronounced as the disease progresses; and supposed that patients adapted to their decreasing vision over time, accepted their reduced level of visual function, or used aids or other strategies to overcome their visual disability. The same reasons can explain the results of this study as the sociocultural and educational levels are not the same. In developing countries like Egypt, there are a lack of aids or adoptions to help the patients; low health facilities with late presentation and poor compliance to the disease ;and lower educational levels with bad understanding of the disease, no follow- up and higher anxiety. Another study had observed that illiterate glaucoma patients fail to understand the nature of their disease even after adequate explanation. ${ }^{(26)}$

\section{Conclusion}

Glaucoma patients have many functional disabilities with challenges in performing many tasks which reflects on their independence and productivity. This knowledge can be helpful to learn the newly diagnosed and to increase the adherence to treatment aiming to guard against the disease progression; also it suggests adaptations to the patient's environment for better quality of life.

\section{References}

1. WHO A. Study protocol for the World Health Organization project to develop a quality of life assessment instrument (WHOQOL). Qual Life Res.1993;2:153.

2. Anonymous. Study protocol for the World Health Organization project to develop a Quality of Life assessment instrument(WHOQOL).Qual Life Res.1993;2:153.

3. Quigley HA. Number of people with glaucoma worldwide.Br J Ophthalmol. 1996;80:389.

4. Hayry M. Measuring the quality of life: why, how, and what? Theor MedBioeth. 1991;12:97.

5. Guyatt G.H., Feeny D.H. \& Patrick D.L. Measuring health-related quality of life. Ann. Intern. Med. 1993;118:622. 
6. Sherwood MB. Essential Outcomes Measures are not acuity,visual field and pressure but rather performance (AFREV) and quality of life. $2003 ; 2: 67$.

7. Vandenbroeck S, De Geest S, Zeyen T, Stalmans I \& Dobbels F.Patient-reported outcomes (PRO's) in glaucoma: a systematic review.Eye (Lond). 2011;25:555.

8. Varma R, Richman EA, Ferris FL \& Bressler NM. Use of patient-reported outcomes in medical product development: a report from the $2009 \mathrm{NEI} / \mathrm{FDA}$ clinical trial endpoints symposium .Investig Ophthalmol Vis Sci 2010;51(12):6095.

9. Severn P, Fraser S, Finch $\mathrm{T} \&$ May C. Which quality of life score is best for glaucoma patients and why. BMC Ophthalmol 2008;8:2.

10. Ware JE \& Gandek B. Overview of the SF36 health survey and the international quality of life assessment project. J Clin Epidemiol 1998;51:903.

11. Bergner M, Bobbit RA, Carter WB \& Gilson BS. The sickness impact profile development and final revision of a health status measure. Med Care 1981;19:787.

12. Steinberg EP, Tielsch JM, Schein OD, Javitt JC, Sharkey P, Cassard SD \& et al. The VF-14: Anindex of functional impairment in patients with cataract. Arch Ophthalmol 1994;112(5):630.

13. Mangione CM, Lee PP, Pitts J, Gutierrez P, Berry S \& Hays RD.. Psychometric properties of the National Eye Institute
Visual Function Questionnaire (NEIVFQ). Arch Ophthalmology 1998;166:1496.

14. Mangione CM, Lee PP, Gutierrez PR, Spritzer K, Berry S \& Hays RD. Development of the 25-item National Eye InstituteVisual Function Questionnaire. Arch Ophthalmol 2001;119:1050.

15. Lee BL, Gutierrez P, Gordon M, Wilson MR, Cioffi GA, Ritch $R$ \& et al. The Glaucoma Symptom Scale. Arch Ophthalmol 1998;166:861.

16. Barber BL, Strahlman ER, Laibovitz R, Guess HA \& Reines SA. Validation Of A Questionnaire For Comparing The Tolerability Of Ophthalmic Medication. Ophthalmology 1997;104:334.

17. Nelson P, Aspinall $\mathrm{P}$, Papasouliotis $\mathrm{O}$, Worton B \& O'Brien C. Quality Of Life In Glaucoma And Its Relationship With Visual Function. J Glaucoma 2003;12:139.

18. Janz NK, Wren PA, Lichter PR, Musch DC, Gillespie BW \& Guire KE. Quality Of Life In Newly Diagnosed Glaucoma Patients: The Collaborative Initial Glaucoma Treatment Study. Ophthalmology 2001;108:887.

19. Onakoya AO, Mbadugha CA, Aribaba OT \& Ibidapo OO. Quality of life of primary open angle glaucoma patients in Lagos, Nigeria: clinical and sociodemographic correlates.J Glaucoma. 2012;21(5):287.

20. Goldberg, I., Clement, C. I., Chiang, T. H., Walt, J. G., Lee, L. J. \& Graham, S. Assessing Quality of Life in Patients With Glaucoma Using the Glaucoma Quality of Life-15 (GQL-15) 
Questionnaire. Journal of Glaucoma, 2009; 18(1), 6 .

21. Ayele FA, Zeraye B, Assefa Y, Legesse K \& Azale T, Burton MJ. The impact of glaucoma on quality of life in Ethiopia: a case-control study. BMC Ophthalmol. 2017 Dec 13;17(1):248.

22. Munish Dhawan, Tania Hans, Pawandeep S Sandhu \& Neha Midha. Evaluation of Vision-related Quality of Life in Patients with Glaucoma: A Hospital-based Study. Journal of Current Glaucoma Practice (2019): 10.5005 .

23. .Zhou, C., Yao, J., Qian, S., \& Wu, P. Linguistic and psychometric validation of the Chinese version of the Glaucoma Quality of Life-15 (GQL-15-CHI): a crosssectional study. Health and Quality of Life Outcomes, 2013;11(1), 188.
24. Mahdaviazad, H., Roustaei, N., Masoumpour, M. B., \& Razeghinejad, M. R. (2018). Psychometric properties of the Glaucoma Quality of Life-15 questionnaire: Use of explanatory factor analysis. Journal of Current Ophthalmology.2017;12.005.

25. Nelson P, Aspinall P, Papasouliotis O, Worton B \& O'Brien C. Quality of life in glaucoma and its relationship with visual function. J Glaucoma 2003;12:139 .

26. Quaranta, L., Riva, I., Gerardi, C., Oddone, F., Floriano, I., \& Konstas, A. G. P. (2016). Quality of Life in Glaucoma: A Review of the Literature. Advances in Therapy, 33(6), 959.

To cite this article: Tarek T. Aboulnasr, Ahmed M. Saeed, Mohamed A. Behery. Glaucoma Quality of Life-15 Questionnaire to Assess the Functional Disability in Egyptian Glaucomatous Patients. BMFJ 2022;39 (ophthalmology):24-37. DOI: 10.21608/bmfj.2021.24031.1214 